\title{
Alkaline-developable and Positive-type Photosensitive Polyimide based on Fluorinated Poly(amic acid) from Diamine with High Hydrophobicity and Fluorinated Diazonaphtoquinone
}

\author{
Yusuke Inoue ${ }^{1}$, Yoshihito Ishida ${ }^{3}$, Tomoya Higashihara ${ }^{2}$, Atsushi Kameyama ${ }^{3}$, \\ Shinji Ando ${ }^{1}$ and Mitsuru Ueda ${ }^{3}$ * \\ ${ }^{1}$ Department of Organic and Polymeric Materials, Graduate School of Science and Engineering, \\ Tokyo Institute of Technology, 2-12-1, O-okayama, 2-12-1-E4-5, Meguro-ku, Tokyo 152-8552, Japan \\ ${ }^{2}$ Department of Polymer Science and Engineering, Yamagata University, \\ 4-3-16, Yonezawa, Yamagata 992-8510, Japan \\ ${ }^{3}$ Department of Chemistry, Kanagawa University, 23-709, \\ 3-27-1, Rokkakubashi, Kanagawa-ku, Yokohama-shi, Kanagawa 221-8686, Japan \\ mueda@kanagawa-u.ac.jp
}

\begin{abstract}
An alkaline-developable positive-type photosensitive polyimide (PSPI) based on fluorinated poly(amic acid) (FPAA) and fluorinated diazonaphtoquinone (FDNQ) as a photoactive compound has been successfully developed as a promising material for use in microelectronics. The FPAA was prepared from 4,4'-(hexafluoroisopropylidene)diphtahlic anhydride and aromatic diamines, 4,4'-oxydianiline ( $80 \mathrm{~mol} \%$ ), and 4,4'-oxybis(4-phenoxyaniline) (20 mol $\%$ ). The PSPI consisting of FPAA, catechol ( $3 \mathrm{wt} \%$ to FPAA), and FDNQ (25 wt \% to FPAA) showed a high sensitivity of $45 \mathrm{~mJ} / \mathrm{cm}^{2}$ and a high contrast of 10 when it was exposed to a 365 $\mathrm{nm}$ line (i-line), and developed with $2.38 \mathrm{wt} \%$ TMAHaq for 10 seconds at room temperature. A clear positive image of a $6-\mu \mathrm{m}$ line and space pattern was printed on a film, which was exposed to $80 \mathrm{~mJ} / \mathrm{cm}^{2}$ of $i$-line by a contact printing mode. Thus, this system will be a good candidate for next generation PSPIs.
\end{abstract}

Keywords: photosensitive polyimide, fluorinated poly(amic acid), fluorinated diazonaphtoquinone, alkaline-developable, positive-type, photoactive compound.

\section{Introduction}

Polyimides (PIs) are some of the best super-engineering plastics and have been widely used in microelectronics, such as a stress buffer and insulation layers due to their excellent thermal, mechanical and reasonable dielectric properties. For use in these applications, micro-fabricating properties using photolithography techniques are required. There are two types of photolithographic processes. One is to make a PI pattern by etching through a photoresist pattern, which is known as the conventional method, and the other is to use photosensitive PIs (PSPIs). PSPIs simplify processing and avoid the use of photoresists in the microelectric industry [1-15]. PSPIs are divided into two types, i.e. the positive and negative types. Recently, much effort have been extended to develop positive-type PSPIs because of their several advantages compared to negative PSPIs, such as a high resolution due to low swelling during development and the use of an alkaline aqueous solution as a developer in place of organic developers. Furthermore, they form a V-type pattern which is suitable for a wire-bonding process. However, the dissolution rate of precursory PAAs in a $2.38 \mathrm{wt} \%$ tetramethyl- 
ammonium hydroxide solution (TMAHaq) used as the aqueous alkaline developer is too high to obtain a sufficient dissolution contrast between the unexposed and exposed areas due to the high acidity of the carboxylic acids in the PAAs. Therefore, only a few TMAHaq-developable positive-type PSPIs have been reported in which highly fluorinated or partially esterified PAAs are used to reduce the dissolution rate in the TMAHaq [16-19]. To decrease the dissolution rate of PAAs in the $2.38 \mathrm{wt} \%$ TMAHaq, more hydrophobic PAAs should be prepared from diamines and/or tetracarboxylic dianhydrides with a high hydrophobicity.

Based on these considerations, we have reported the PSPI consisting of the fluorinated PAA (FPAA) obtained from 4,4'-(hexafluoroisopropylidene)diphtahlic anhydride (6FDA), 4,4'-oxydianiline (ODA), and a new fluorinated diazonaphthoquinone (FDNQ) as a photoactive compound prepared by the reaction of 1,2-naphthoquinone-2-diazo-5-sulfonyl chloride with 4,4'-(hexafluoroisopropylidene)diphenol [20]. In this system, the FDNQ is spontaneously segregated at the surface of the film during the prebaking step due to the high polarity difference between FPAA and FDNQ. Thus, the dissolution rate in the $2.38 \mathrm{wt} \%$ TMAHaq significantly decreases on the surface of the film. This PI patterning is simple, but still requires more than a $120 \mathrm{~mJ} / \mathrm{cm}^{2}$ dose and $2.38 \mathrm{wt} \%$ TMAHaq containing isopropyl alcohol (IPA). In addition, the development time was very short, only one second. Thus, a novel PSPI should be developed to remedy these problems, and be suitable for use in a practical process.

This article describes the development of an alkaline developable and positive-type PSPI consisting of the FPAA from 6FDA, ODA, 1,4-bis(4-aminophenoxy)benzene (APB), and FDNQ in which APB with high hydrophobicity was introduced to reduce the solubility of FPAA in the alkaline developer. Scheme 1 shows the photolithographic process. The solution of FPAAx and FDNQ is spin-coated on a silicon wafer and prebaked. The FDNQ rich top layer is spontaneously formed. The film is then exposed to the $i$-line through a photomask to produce an indenecarboxylic acid by a photochemical reaction.
The indenecarboxylic acid is extremely soluble in the alkaline aqueous developer. As a result, the dissolution rate of the exposed area to the 2.38 wt $\%$ TMAHaq increases and a positive image is formed. The new PSPI possesses several advantages over previous TMAHaq-developable and positive-type PSPIs, such as a higher sensitivity for the PI patterning and longer development time. Furthermore, the development is carried out with $2.38 \mathrm{wt} \%$ TMAHaq without using IPA.

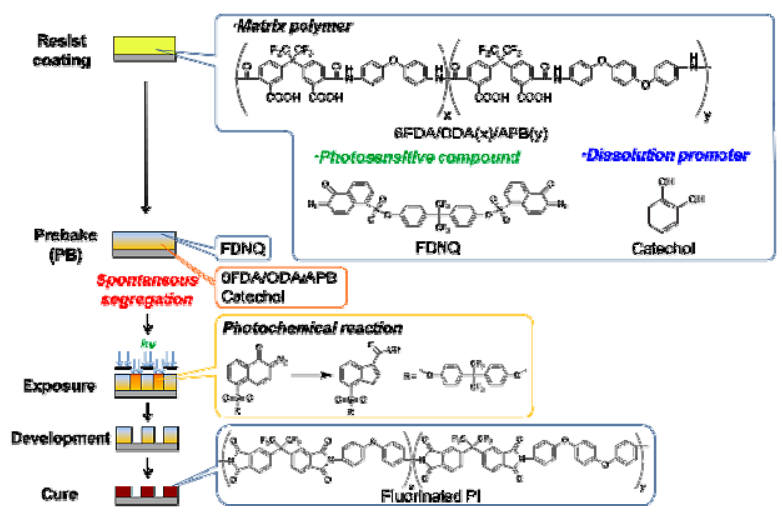

Scheme 1. Patterning process of the resist based on FPAAx and FDNQ

\section{Experimental}

2-1. Marerials

$N, N$-Dimethylacetamide (DMAc) and tetrahydrofuran (THF) were purified by vacuum distillation. The commercially available monomers, 4,4'-oxydianiline (ODA), 1,4-bis(4-aminophenoxy)benzene (APB) and 4,4'-(hexafluoroisopropylidene)diphthalic anhydride (6FDA) were purchased from Tokyo Chemical Industry Co., Ltd. 6FDA was purified by vacuum sublimation. The new fluorinated diazonaphthoquinone (FDNQ) was prepared from 1,2-naphthoquinone-2-diazo-5-sulfonyl chloride with 4,4'-(hexafluoroisopropylidene) diphenol according to our previous paper [19]. A $2.38 \mathrm{wt} \%$ TMAH aqueous solution was used as a standard developer. Other reagents and solvents were used as received.

2-2. Synthesis of FPAA from 6FDA, ODA and APB

6FDA $(0.444 \mathrm{~g}, 1.00 \mathrm{mmol})$ was added to a 
solution of ODA $(0.168 \mathrm{~g}, 0.84 \mathrm{mmol})$ and APB $(0.061 \mathrm{~g}, 0.21 \mathrm{mmol})$ in DMAc $(3.81 \mathrm{~mL})$. This solution was stirred at room temperature for $1 \mathrm{~h}$. An inherent viscosity of the FPAA in DMAc was $0.32 \mathrm{dL} \mathrm{g}^{-1}$ at a concentration of $0.5 \mathrm{~g} \mathrm{dL}^{-1}$ in DMAc at $30{ }^{\circ} \mathrm{C}$.

\section{2-3. Degree of imidization.}

The polymer solution (FPAA) was diluted with DMAc to a concentration of $15 \mathrm{wt} \%$. This solution was spin-coated on a silicon wafer, baked at $80{ }^{\circ} \mathrm{C}$ for $60 \mathrm{~min}$ in air. The film thickness was about 1.1-1.2 $\mu \mathrm{m}$. Then, the films were baked on a hot-plate at each temperature $\left(100-250{ }^{\circ} \mathrm{C}\right)$ for 5 min. A reference PI film was prepared by heating at $250{ }^{\circ} \mathrm{C}$ for $0.5 \mathrm{~h}$ and $350{ }^{\circ} \mathrm{C}$ for $1 \mathrm{~h}$. Absorption intensities on a FTIR spectrum at $1376 \mathrm{~cm}^{-1}\left(\mathrm{~A}_{1376}\right)$ attributed to the $\mathrm{C}-\mathrm{N}$ stretching of an imide group and at $1500 \mathrm{~cm}^{-1} \quad\left(\mathrm{~A}_{1500}\right)$ attributed to $\mathrm{C}=\mathrm{C}$ stretching of a phenyl group were measured, and the degrees of imidization were determined using the following equation;

$$
\operatorname{Imidization}(\%)=\frac{\frac{\mathrm{A}_{1376}}{\mathrm{~A}_{1500(\text { samp })}}-\frac{\mathrm{A}_{1376}}{\mathrm{~A}_{1500(\text { init })}}}{\frac{\mathrm{A}_{1376}}{\mathrm{~A}_{1500(\text { (imide) }}}-\frac{\mathrm{A}_{1376}}{\mathrm{~A}_{1500 \text { (init) }}}}
$$

where subscripts between parentheses that followed $\mathrm{A}_{1376} / \mathrm{A}_{1500}$ in the equation indicate the states of the polymer films; for example, (samp) is the polymer sampled at each heating temperature $\left(100-250{ }^{\circ} \mathrm{C}\right)$; (init) is initially prebaked PAA at $80{ }^{\circ} \mathrm{C}$ for $1 \mathrm{~h}$ and (imide) is the fully cured polymer at $250{ }^{\circ} \mathrm{C}$ for $0.5 \mathrm{~h}$ and $350{ }^{\circ} \mathrm{C}$ for $1 \mathrm{~h}$ in air.

\section{2-4. Dissolution rate.}

FDNQ was added into the mixture of FPAA solution in DMAc (the total solid content was 15 wt \%). The resist films with $1.2 \mu \mathrm{m}$ thickness were obtained by spin-coating from the solutions on silicon wafers. These films were pre-baked under each condition, then exposed to a filtered super-high pressure mercury lamp at $365 \mathrm{~nm}$ (i-line). The dissolution rate $(\AA / \mathrm{sec})$ of the film was determined from changes in the film thickness before and after the development with the 2.38 $\mathrm{wt} \%$ TMAHaq followed by rinsing with water.

\section{2-5. Photosensitivity.}

The photosensitive polymer film with $1.2 \mu \mathrm{m}$ thickness was prepared by dissolving $25 \mathrm{wt} \%$ of FDNQ in the FPAA solution in DMAc, followed by spin-coating on a silicon wafer and prebaking at $120{ }^{\circ} \mathrm{C}$ for $2 \mathrm{~min}$, exposure to irradiation at a wavelength of $i$-line with changing an exposure dose, development with $2.38 \mathrm{wt} \%$ TMAHaq for 10 $\mathrm{sec}$ at room temperature, and rinsing with water. A characteristic photosensitive curve was obtained by plotting a normalized film thickness against the exposure dose (unit: $\mathrm{mJ} / \mathrm{cm}^{2}$ ).

\section{2-6. Measurements}

The infrared spectroscopy (IR) was carried out with a Horiba FT- 210 spectrophotometer. The ${ }^{1} \mathrm{H}$ and ${ }^{13} \mathrm{C}$ NMR spectra were obtained on a BRUKER DPX-300S spectrometer $\left({ }^{1} \mathrm{H}\right.$ at 300 $\mathrm{MHz}$ and ${ }^{13} \mathrm{C}$ at $75 \mathrm{MHz}$ ). Deuterated chloroform $\left(\mathrm{CDCl}_{3}\right)$ and dichloromethane $\left(\mathrm{CD}_{2} \mathrm{Cl}_{2}\right)$ were used as solvents with tetramethylsilane as an internal standard. Elemental analyses were performed on a Yanaco MT-6 CHN CORDER with antipyrine as a standard sample. Viscosity measurements were carried out using an Ostwald viscometer at $30{ }^{\circ} \mathrm{C}$ in DMAc. The contact angles of water were measured by placing drops of distilled water on the prepared films using a microscope goniometer (Kyowa Interface Science CA-A) at $25{ }^{\circ} \mathrm{C}$. The film thickness was measured with a Veeco Instrument Dektak3 surface profiler. Field emission scanning electron micrographs (FE-SEM) were taken using Hitachi S4500. Pt/Pd was sputtered on films before the SEM measurement.

\section{Results and Discussion}

3-1. Lithographic Evaluation

The dissolution rate of PAA in $2.38 \mathrm{wt} \%$ TMAHaq may depend on the weight percent of the carboxylic acid in the repeating unit. Therefore, the use of a diamine with a high molecular weight would be effective to reduce the dissolution rate of PAA. Based on this reasoning, APB was selected as a diamine with a high molecular weight.

FPAAs were prepared from 6FDA, ODA, and APB by changing the molar ratio of ODA and 
APB (Scheme 2). The inherent viscosities of these FPAAs in DMAc were controlled around $0.3 \mathrm{dLg}^{-1}$ at a concentration of $0.5 \mathrm{gdL}^{-1}$ at $30^{\circ} \mathrm{C}$.

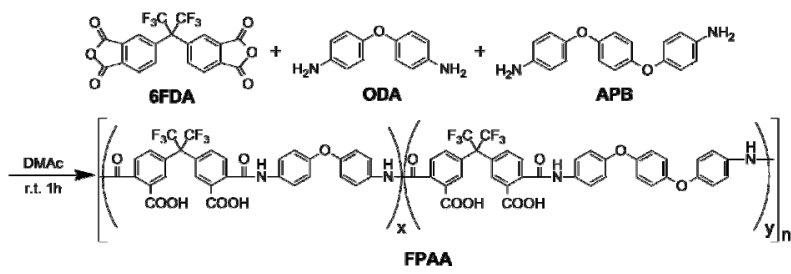

Scheme 2. Synthesis of FPAA

To understand the dissolution behavior of the resulting FPAAs in the $2.38 \mathrm{wt} \%$ TMAHaq, a FPAA solution in DMAc was spin-coated on a silicon wafer and prebaked at $120{ }^{\circ} \mathrm{C}$ for $2 \mathrm{~min}$. The film with a $1.0 \mu \mathrm{m}$ thickness was developed with the $2.38 \mathrm{wt} \%$ TMAHaq at room temperature. The results are summarized in Table 1 .

Table 1 Dissolution rate of FPAA

\begin{tabular}{lr}
\hline & $\begin{array}{c}\text { Dissolution rate } \\
\text { Polymer } \\
{[\AA / \mathrm{sec}]}\end{array}$ \\
\hline FPAA-0(ODA:APB=100:0)* & 14000 \\
FPAA-0(FDNQ) & 5500 \\
\hline FPAA-1(ODA:APB=90:10)* & 12000 \\
FPAA-1(FDNQ) & 2600 \\
\hline FPAA-2(ODA:APB=80:20)* & 8000 \\
FPAA-2(FDNQ) & 1200 \\
\hline FPAA-3(DA:APB=70:30)* & 6000 \\
FPAA-3(FDNQ) & swelling \\
\hline
\end{tabular}

*mole ratio

Although the FPAA shows a very high dissolution rate around $14,000 \AA / \mathrm{sec}$, the dissolution rate of FPAA-x decreases with the increasing molar ratios of $\mathbf{A P B} / \mathbf{O D A}$, and that of FPAA-3 drops to $6,000 \AA /$ sec. These dissolution behaviors of the resulting FPAA-x clearly support our speculation. The effect of the FDNQ loading $(25 \mathrm{wt} \%)$ on the dissolution rate of the film was then studied (Table 1). The dissolution rate of the films containing FDNQ was effectively decreased and that of FPAA-2 reduced to $1,200 \AA / \mathrm{sec}$. On the other hand, a swelling behavior was observed in FPAA-3 probably due to the high hydrophobicity of APB.

Based on these findings, the effects of the APB contents, prebake (PB) temperature, FDNQ loading, and amounts of catechol as a dissolution promoter were investigated to obtain contrasting pattern profiles from the exposed and unexposed areas.

The films were obtained by spin-casting diluted polymerization solutions of FPAA containing FDNQ on a silicon wafer, and then prebaking at a set temperature for $2 \mathrm{~min}$ in air. These photosensitive polymer films were irradiated with UV light at $365 \mathrm{~nm}$ (i-line) using a filtered super high pressure mercury lamp, and developed with ᄀ $38 \mathrm{wt} \%$ TMAHaq at $25^{\circ} \mathrm{C}$.

214 First, the effect of the APB contents on the dissolution rate of the film was investigated (Fig. 1) in which each film was prebaked at $120{ }^{\circ} \mathrm{C}$ for $2 \mathrm{~min}$, and exposed to $80 \mathrm{~mJ} / \mathrm{cm}^{2}$. The dissolution rate of the unexposed area abruptly decreases by the increasing APB contents, and becomes almost zero in $20 \mathrm{~mol} \%$ of APB to ODA, while the exposed area is rapidly dissolved in the developer. The dissolution contrast (DC) between the exposed and unexposed areas in the 2.38 wt \% TMAHaq reached 10,000 times. Moreover, the development time could be extended to $10 \mathrm{sec}$ by the introduction of hydrophobic APB in the FPAA. Thus, the FPAA-2 solution was formulated for the following lithographic evaluation.

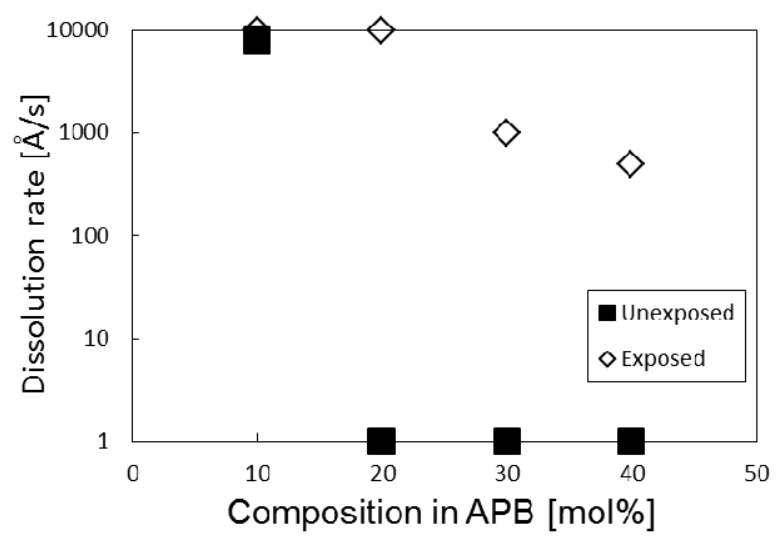

Fig.1 Effect of APB contents on the dissolution rate of the exposed and unexposed films (FPAA and FDNQ (25 $\mathrm{wt} \%$ to FPAA)). The $i$-line exposure dose, PB temperature and $\mathrm{PB}$ time were fixed to $80 \mathrm{~mJ} / \mathrm{cm}^{2}, 120$ ${ }^{\circ} \mathrm{C}$ and $2 \mathrm{~min}$, respectively. 
The PB temperature is crucial in this system to obtain a high dissolution contrast between the exposed and unexposed areas because the PB temperature directly affects the phase separation behavior. Thus, the effect of the PB temperature was investigated and the results are summarized in Fig. 2. The dissolution rate in the unexposed area decreases with the increasing PB temperature. Very high dissolution contrasts were obtained at $120{ }^{\circ} \mathrm{C}$ for $2 \mathrm{~min}$, indicating that the phase separation was efficiently promoted within a short PB time at $120^{\circ} \mathrm{C}$.

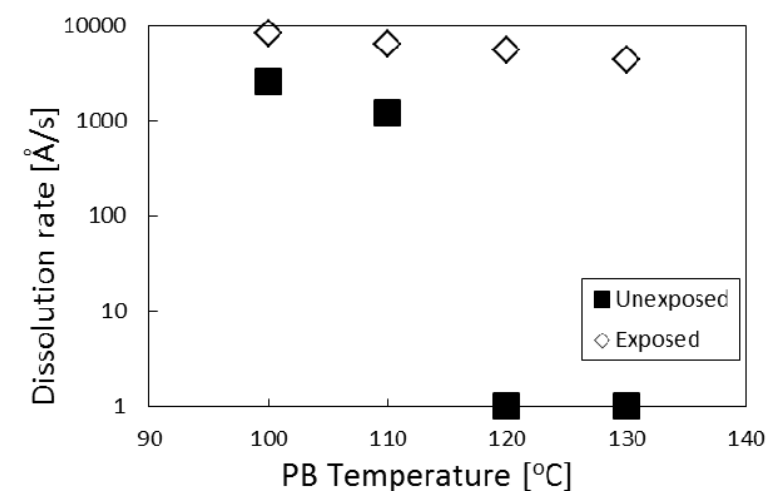

Fig. 2 Effect of PB temperature on the dissolution rate of the exposed and unexposed films (FPAA-2 and FDNQ (25 $\mathrm{wt} \%$ to FPAA-2)). The $i$-line exposure dose and $\mathrm{PB}$ time were fixed to $80 \mathrm{~mJ} / \mathrm{cm}^{2}$ and $2 \mathrm{~min}$, respectively.

To clarify this behavior, the contact angles of water to the film consisting of FPAA-2 and FDNQ $(25 \mathrm{wt} \%)$ was measured at each temperature for 2 min. Fig. 3 shows the changes in their contact angles which gradually increase with the increasing PB temperatures, indicating that the phase segregation of FDNQ is effectively promoted during the PB treatment.

Since the highest dissolution contrast was obtained after the PB treatment for $2 \mathrm{~min}$, the following lithographic evaluation was conducted based on the PB condition at $120{ }^{\circ} \mathrm{C}$ for $2 \mathrm{~min}$. In a similar way, the effect of the FDNQ loading on the dissolution rate was investigated with the FPAA-2. The $25 \mathrm{wt} \%$ FDNQ loading for the amount of FPAA-2 is required to obtain a large dissolution contrast between the exposed and unexposed areas (Fig. 4).

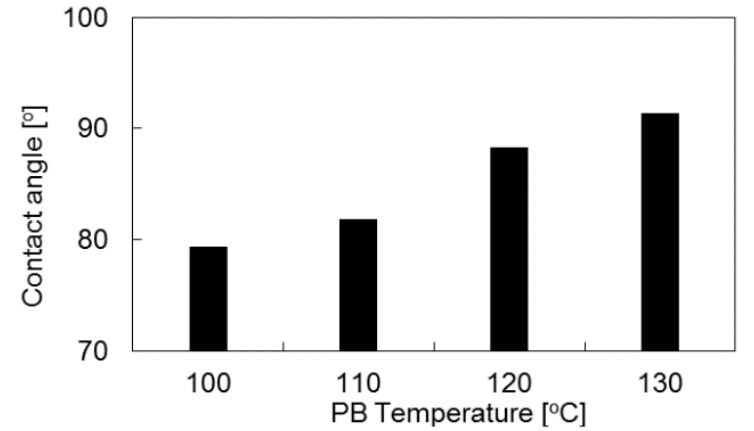

Fig. 3 Contact angles of the films after PB. The films consisting of FPAA-2 and FDNQ (25 wt $\%$ to FPAA) were used. The PB time was fixed at $2 \mathrm{~min}$.

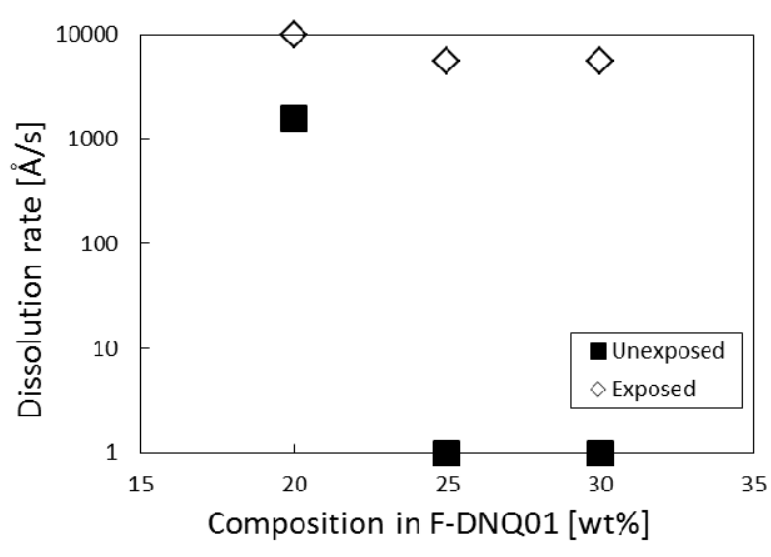

Fig. 4 The effect of FDNQ contents on the dissolution rate of the exposed and unexposed films. The $i$-line exposure dose and $\mathrm{PB}$ condition were fixed to 80 $\mathrm{mJ} / \mathrm{cm}^{2}, 120{ }^{\circ} \mathrm{C}$ for $2 \mathrm{~min}$, respectively.

The dissolution rates of the exposed area are also expected to decrease with the increasing PB temperature due to the imidization of the PAAs. Thus, the degree of imidization (DI) in the FPAA-2 was determined by IR spectroscopy. The DIs were obtained using Eq. (1) and the results are summarized in Table 2. The DIs after the PB treatment up to $130{ }^{\circ} \mathrm{C}$ are less than $3 \%$, indicating that a large dissolution contrast between the exposed and unexposed areas results from the phase separation.

During the course of our investigation, we found that a very thin film remained on a silicon wafer after development. This may be attributed to the strong hydrogen bond interaction between the PAAs and hydroxyl groups of the silicon wafers. 3,4-Dihydroxyphenylalanine (DOPA) is a 
Table 2 Degree of Imidization for FPAA-2 after Prebaking

\begin{tabular}{|c|c|c|c|c|c|c|c|}
\hline Prebaking & $\begin{array}{l}\text { Temp. } \\
{ }^{\circ} \mathrm{C}\end{array}$ & 80 & 100 & 110 & 120 & 130 & 350 \\
\hline Condition & $\begin{array}{l}\text { Time } \\
\text { min }\end{array}$ & 60 & 2 & 2 & 2 & 2 & 60 \\
\hline $\begin{array}{c}\text { Degree of } \\
\text { imidization } \\
(\%)\end{array}$ & FPAA & 0 & 0 & 0.8 & 1.72 & 2.71 & 100 \\
\hline
\end{tabular}

well-known adhesive for various substrates in which catechols enhance the interfacial adhesion of materials [21-22]. Thus, catechol would interact with the hydroxyl groups of the silicon wafers, reducing the hydrogen bond between the PAAs and silicon wafers.

To remove this thin film, catechol was added to the PSPI solution. The PSPI film was completely removed by the addition of $3 \mathrm{wt} \%$ catechol to FPAA-2 after development with 2.38 wt $\%$ TMAHaq.

Based on these preliminary optimization studies, the PSPI containing FPAA-2, FDNQ (25 $\mathrm{wt} \%$ to FPAA-2) and catechol (3 $\mathrm{wt} \%$ to FPAA-2) was formulated. The photosensitive curve of the resist films with a $1.2 \mu \mathrm{m}$ thickness is shown in Fig. 5 . The PSPI had an excellent sensitivity of 45 $\mathrm{mJ} / \mathrm{cm}^{2}$ and a good contrast of 10 with $i$-line exposure.

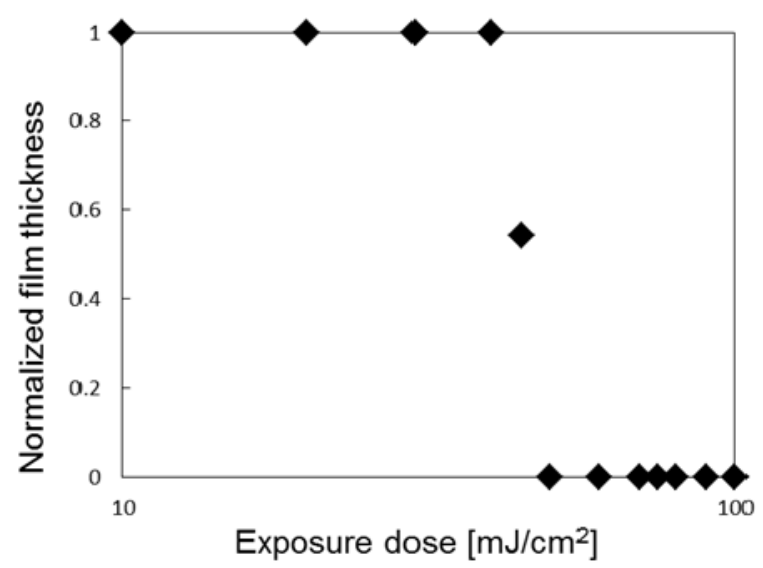

Fig. 5 Characteristic photosensitive curve of PSPI (FPAA-2 and FDNQ (25 wt $\%$ to FPAA-2)) in the $1.8-\mu \mathrm{m}$-thick film. The PB condition was fixed to 120 ${ }^{\circ} \mathrm{C}$ for $2 \mathrm{~min}$, respectively.

The SEM image of the contact-printed pattern was obtained using the PSPI film (Fig. 6). The
PSPI consisting of FPAA-2, and FDNQ (25 wt $\%$ ), and catechol $(3 \mathrm{wt} \%)$ was prebaked at $120{ }^{\circ} \mathrm{C}$ for 2 min, exposed to $80 \mathrm{~mJ} / \mathrm{cm}^{2}$ of the $i$-line, and developed with $2.38 \mathrm{wt} \%$ TMAHaq for $10 \mathrm{sec}$. Consequently, a clear positive pattern was successfully obtained with a $6 \mu \mathrm{m}$ feature on a 1.2 $\mu \mathrm{m}$ thick film.

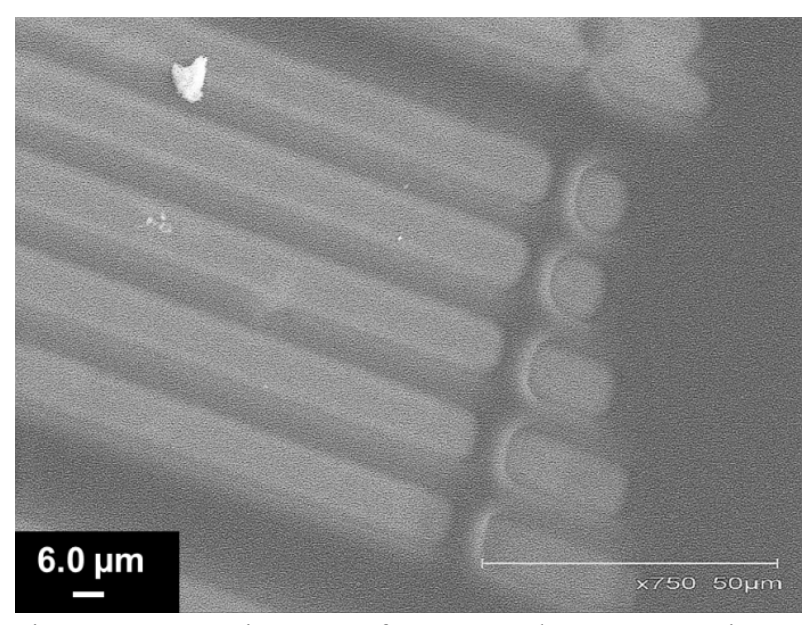

Fig. 6 SEM image of patterned FPAA-2 in a 1.2- $\mu \mathrm{m}$-thick film (FPAA-2 and FDNQ (25 wt $\%$ to FPAA2)). The $i$-line exposure dose and $\mathrm{PB}$ condition were fixed to $80 \mathrm{~mJ} / \mathrm{cm}^{2}$ and $120{ }^{\circ} \mathrm{C}$ for $2 \mathrm{~min}$, respectively $(3.0 \mathrm{kV}$ x $1.30 \mathrm{k})$.

The printed FPAA pattern was cured to obtain the PI pattern by heating at elevated temperatures up to $250^{\circ} \mathrm{C}$ for $30 \mathrm{~min}$ and then at $350{ }^{\circ} \mathrm{C}$ for $1 \mathrm{~h}$ under Nitrogen (Fig. 7). The film thickness decreased from 1.2 to $1.0 \mu \mathrm{m}$ due to a cyclodehydration and decomposition of FDNQ. However, no damage to the formed patterns was observed. The IR spectrum after curing indicated that the PAA films were successfully converted to the PI films.

\section{Conclusion}

FPAAs with an appropriate dissolution rate in $2.38 \mathrm{wt} \%$ TMAHaq were prepared by the polymerizations of 6FDA, ODA, and APB. An alkaline developable and positive-type PSPI based on FPAA-2, FDNQ and catechol was successfully developed. The resist solution was spin-coated on a silicon wafer and prebaked, spontaneously forming the FDNQ rich surface on the film, that is, a top FDNQ rich layer and a 


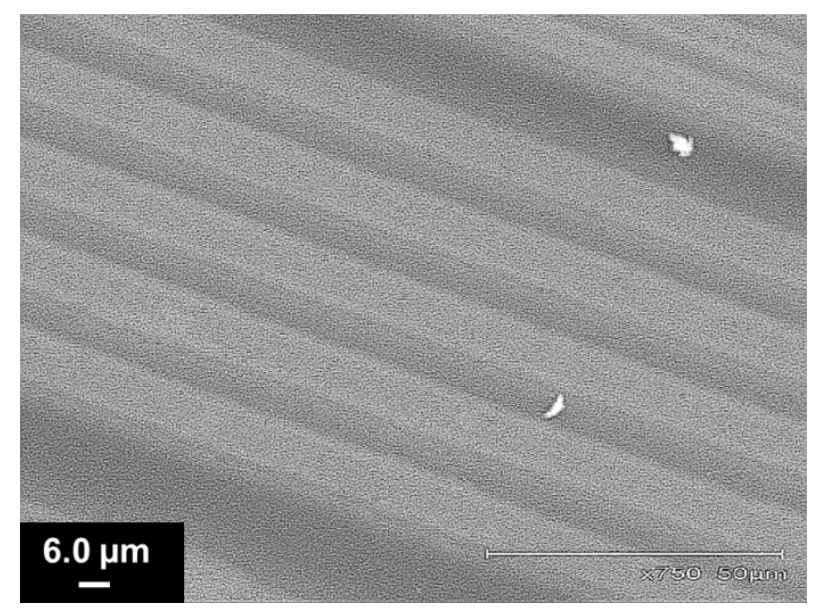

Fig. 7 SEM image of the positive-patterned PI film by thermal curing at $250{ }^{\circ} \mathrm{C}$ for $30 \mathrm{~min}$ and then $350{ }^{\circ} \mathrm{C}$ for $1 \mathrm{~h}$ under Nitrogen $(3.0 \mathrm{kV}$ x $1.30 \mathrm{k})$.

bottom FDNQ less layer of FPAA-2 with PB treatment. The exposed compartment of the thin top layer of FPAA-2 with rich FDNQ was developed with $2.38 \mathrm{wt} \%$ TMAHaq, producing a positive pattern. Subsequently, the FPAA-2 bottom layer containing less FDNQ was developed under the pattern of the top layer. The PSPI exhibited an excellent sensitivity of 45 $\mathrm{mJ} / \mathrm{cm}^{2}$ and a good contrast of 10 with $i$-line exposure, and delineated a fine positive pattern of $6 \mu \mathrm{m}$. This positive-type PSPI resist system can be one of the candidates for the next generation microchip fabrication processes which can provide a facile formulation of PSPI.

\section{References}

1. M. K. Ghosh and K. L. Mittal, Polyimides: Fundamentals and Applications, Marcel Dekker, New York, 1996.

2. A. Mochizuki, T. Teranishi, M. Ueda and K. Matsushita, Polymer, 36 (1995) 2153-2158.

3. A. Mochizuki, T. T. Teranishi and M. Ueda, Macromolecules, 28 (1995) 365-369.

4. M. Ueda and T. Nakayama, Macromolecules, 29 (1996) 6427-6431.
5. T. Nakayama, A. Mochizuki and M. Ueda, React. Funct. Polym, 30 (1996) 109-115.

6. A. Mochizuki and M. Ueda, J. Photopolym. Sci. Technol, 14 (2001) 677-687.

7. T. Fukushima, T. Oyama, T. Iijima, M. Tomoi and H. Itatani, J. Polym. Sci., Part-A: Polym. Chem, 39 (2001) 3451-3463.

8. Y. Watanabe, K. Fukukawa, Y. Shibasaki and M. Ueda, J. Polym. Sci., Part-A: Polym. Chem,. 43 (2005) 593-599.

9. Y. Watanabe, Y. Shibasaki, S. Ando and M. Ueda, Polym. J., 37 (2005) 270-276.

10. S. H. Pyo, M. Y. Lee, J. J. Jeon, J. H. Lee, M. H. Yi and J. S. Kim, Adv. Funct. Mater., 15 (2005) 619-626.

11. K. Sakayori, Y. Shibasaki and M. Ueda, J. Polym. Sci., Part-A: Polym. Chem., 44 (2006) 6385-6393.

12. G. J. Shin, J. C. Jung, J. H. Chi, T. H. Oh and J. B. Kim, J. Polym. Sci., Part-A: Polym. Chem., 45 (2007) 776-788.

13. K. Fukukawa and M. Ueda, Polym. J., 40 (2008) 281-296.

14. T. Li and S. L. Hsu, J. Polym. Sci., Part-A: Polym. Chem., 47 (2009) 1575-1583

15. Y. Saito, K. Mizoguchi, T. Higashihara and M. Ueda, J. Appl. Polym. Sci., 113 (2009) 3605-3611.

16. M. Tomikawa, S. Yoshida and N. Okamoto, Polym. J., 42 (2009) 604-608.

17. O. Haba, M. Okazaki, T. Nakayama and M. Ueda, J. Photopolym. Sci. Technol., 10 (1997) 55-60.

18. H. Seino, A. Mochizuki, O. Haba and M. Ueda, J. Polym. Sci., Part-A: Polym. Chem., 36 (1998) 2261-2267.

19. Y. Inoue, Y. Saito, T. Higashihara and M. Ueda, J. Mater. Chem. C., 1 (2013) 2553-2560

20. Y. Inoue, T. Higashihara and M. Ueda, $J$. Photopolym. Sci. Technol., 26 (2013) 351-356

21. J. H. Waite and M. L. Tanzer, Science, 212 (1981) 1038-1040.

22. M. Yu, T. J. Deming, Macromolecules, 31 (1998) 4739-4745. 